\title{
¿USGS
}

\section{Seismicity of the Earth 1900-2010}

Caribbean Plate and Vicinity

Compiled by Harley M. Benz,' Arrthur C. Tarr,' Gavin P. Hayes,' Antonio Villaseñor,'2 Kevin P. Furlong,' Richard L. Dart,' and Susan Rhe

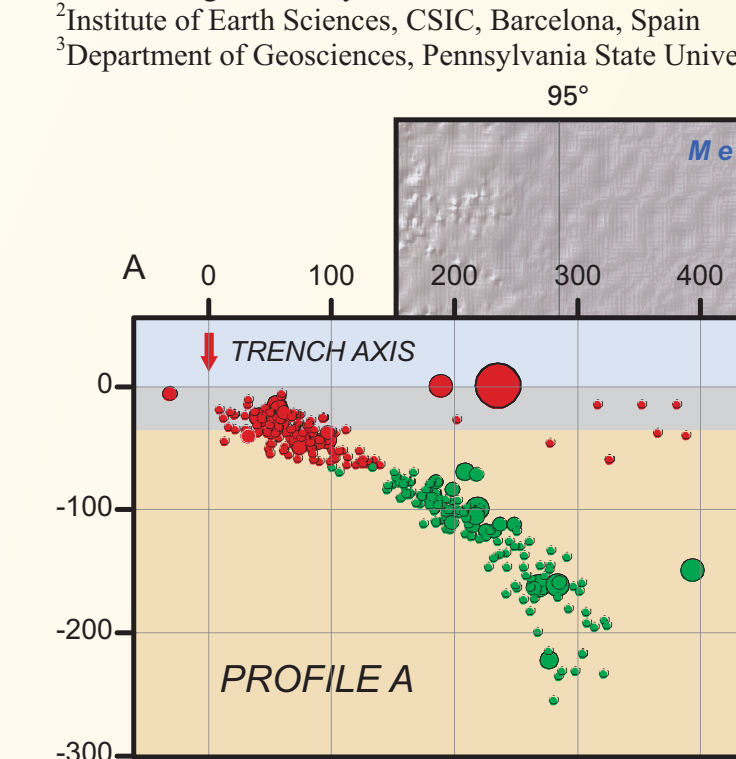

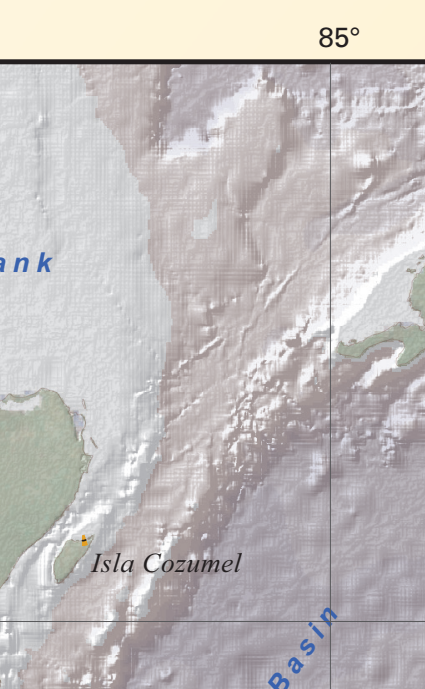

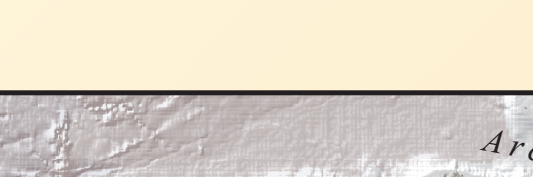

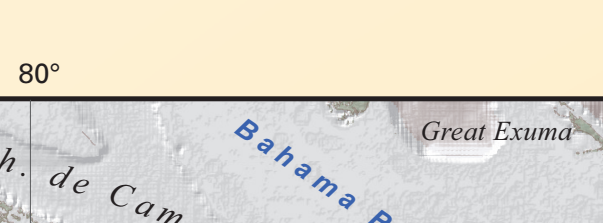

\section{$15^{\circ}$}
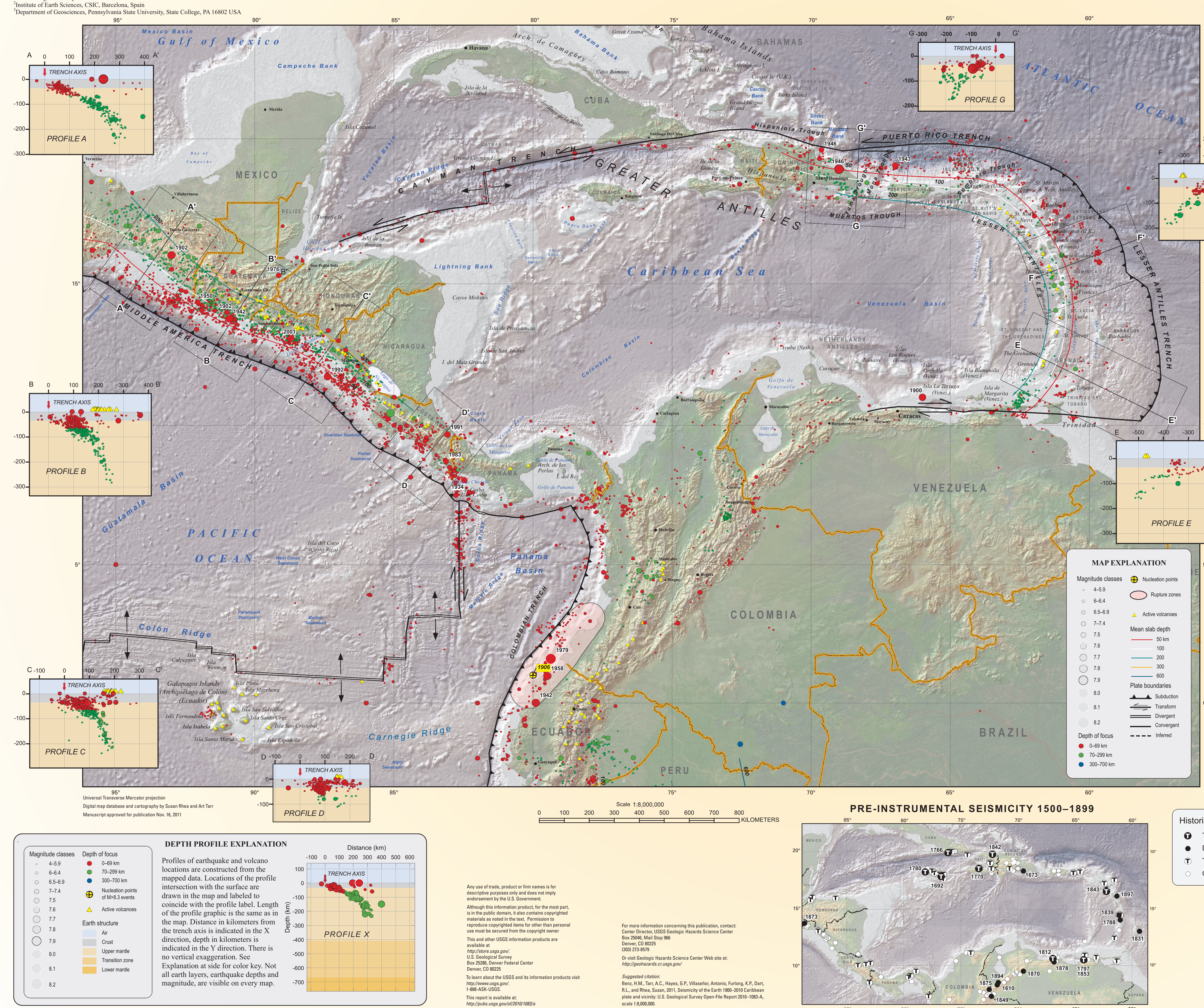
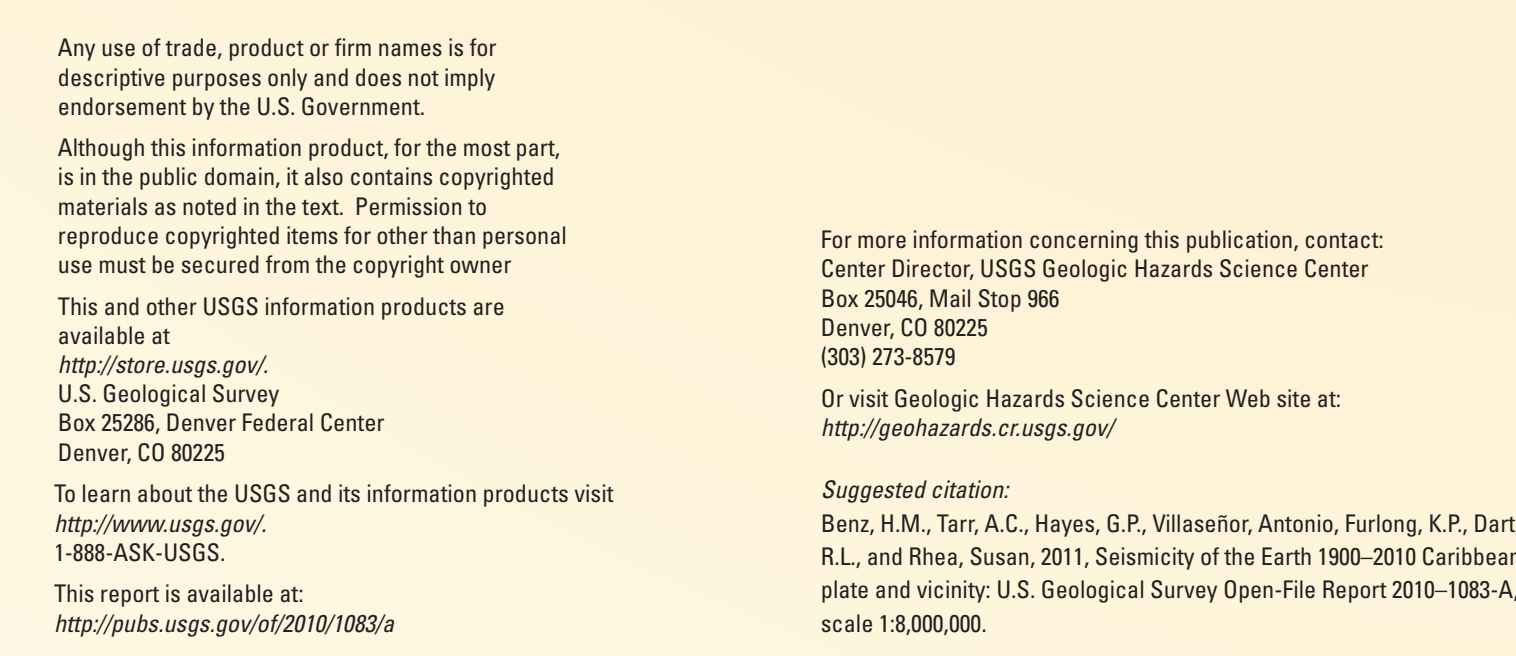

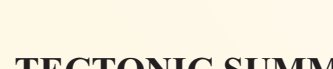

OPEN-FILE REPORT 2010-1083-A
Revised September, 2011

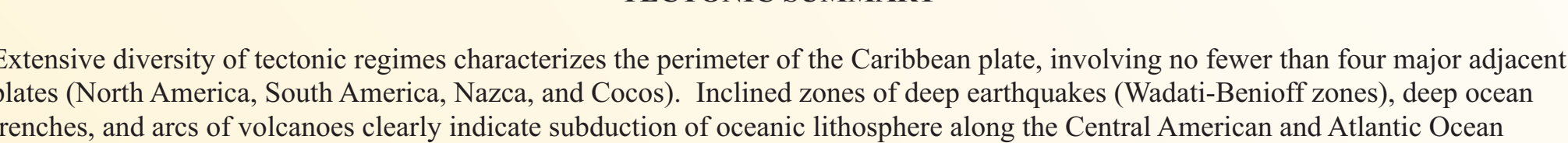

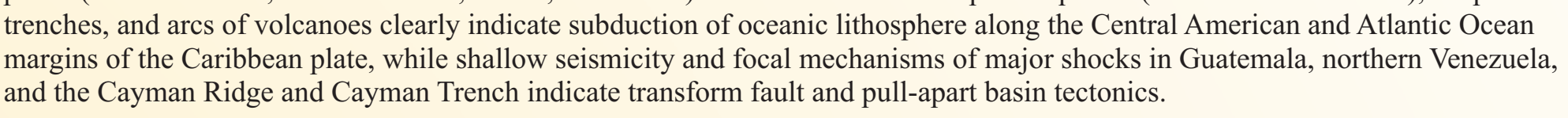

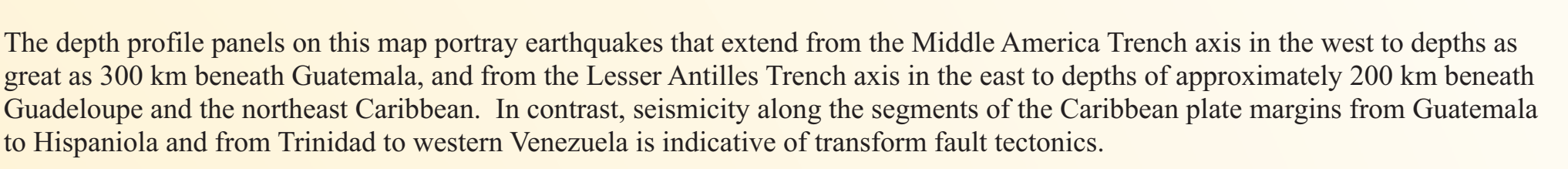

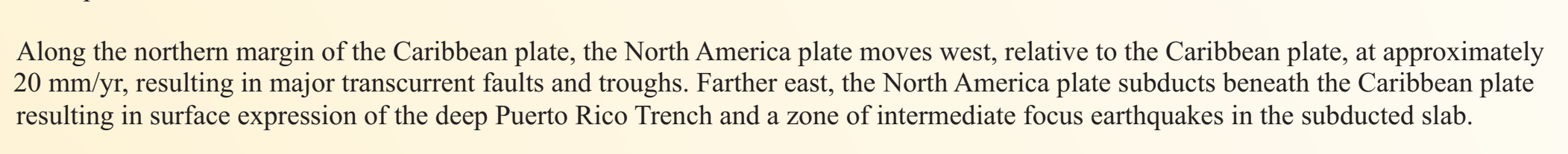

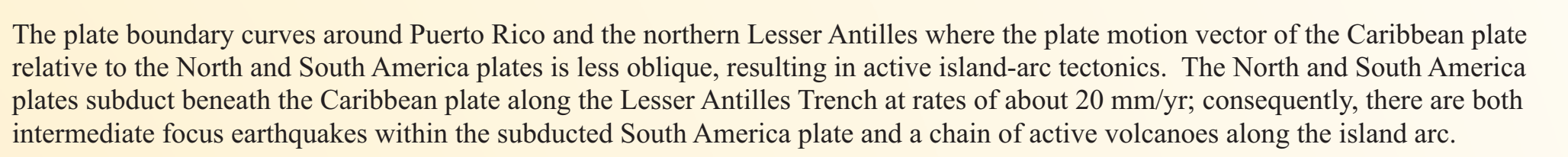

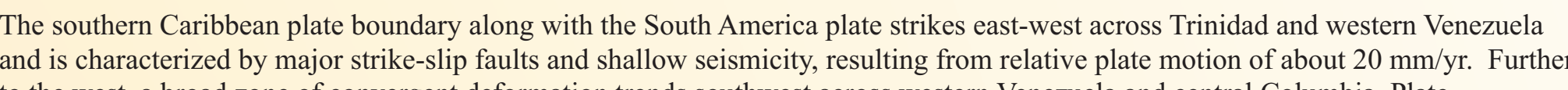

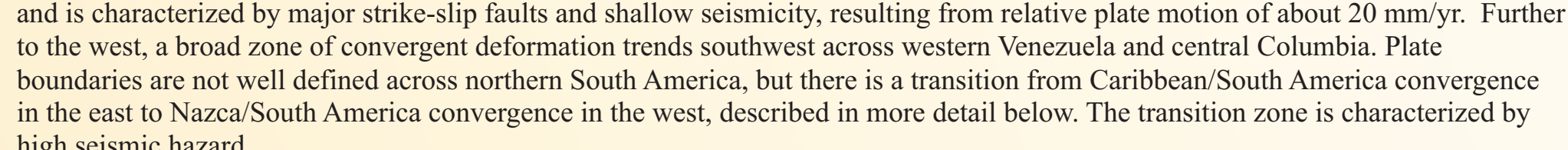

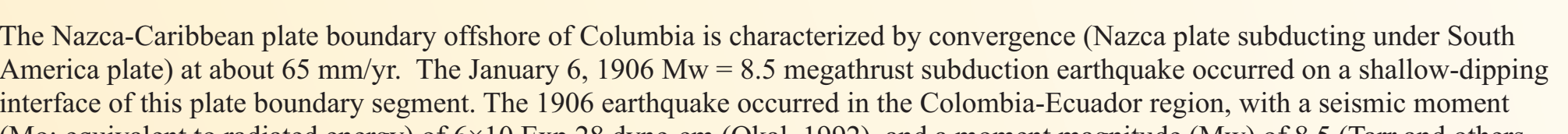

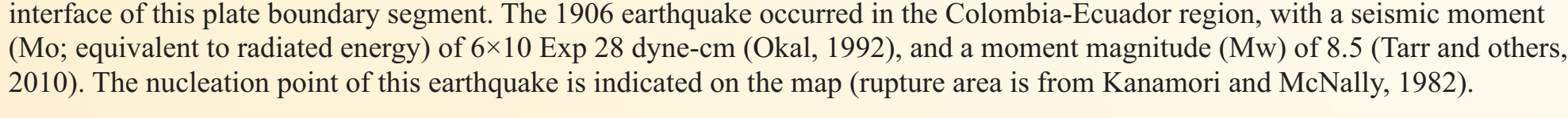

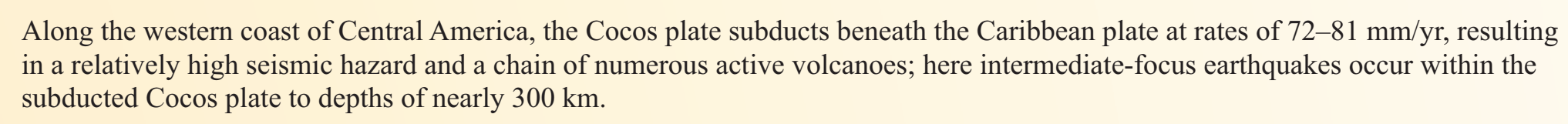
DATA SOURCEs

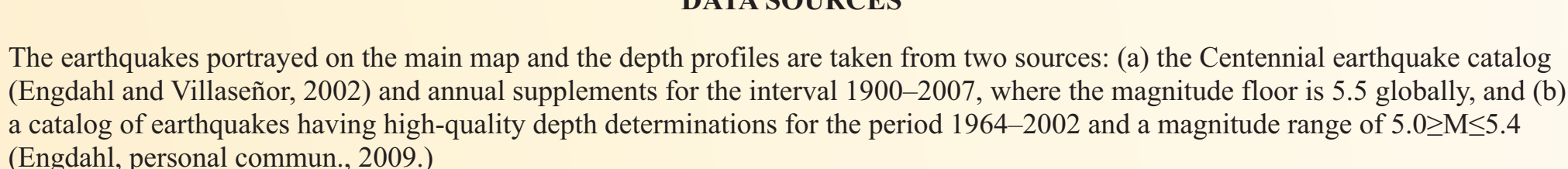

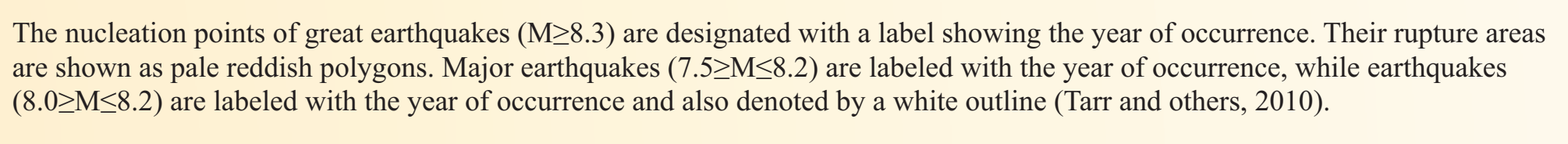

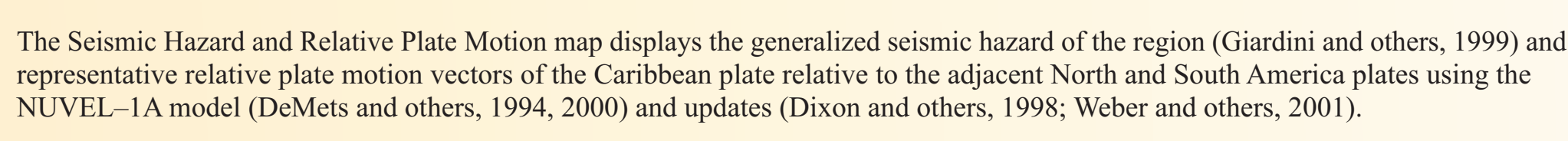

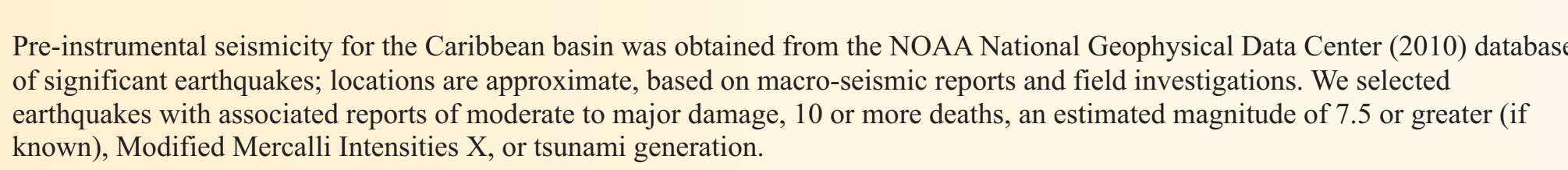

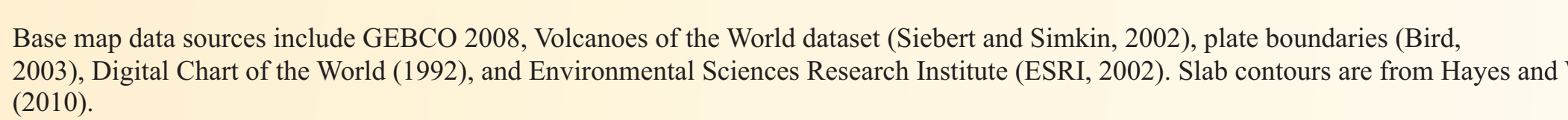
REFERENCES

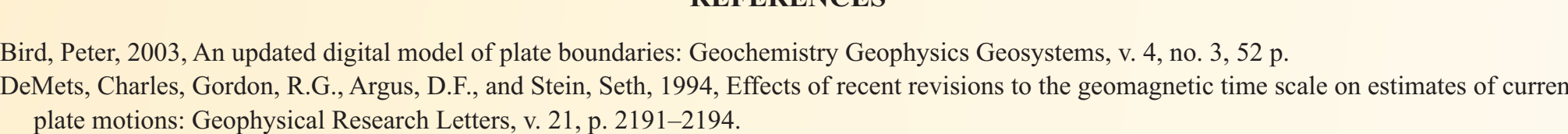

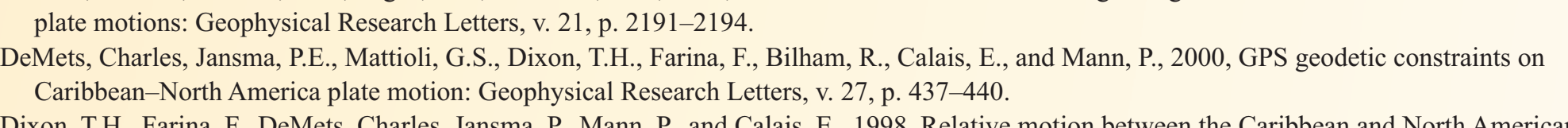

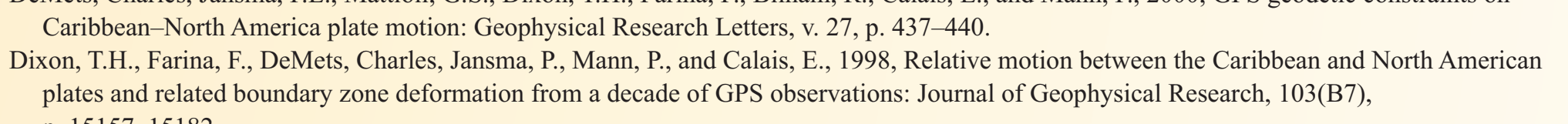

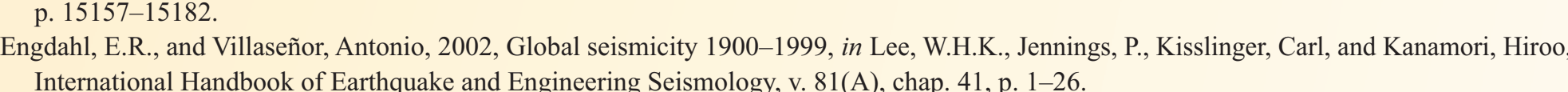

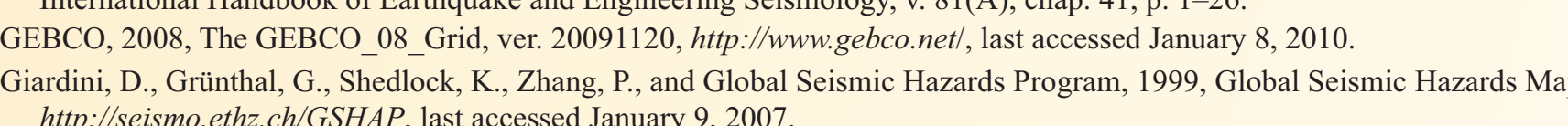

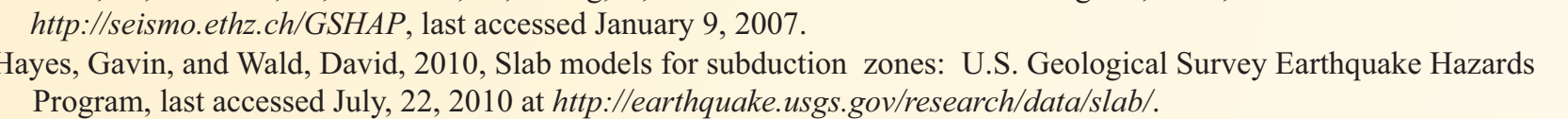

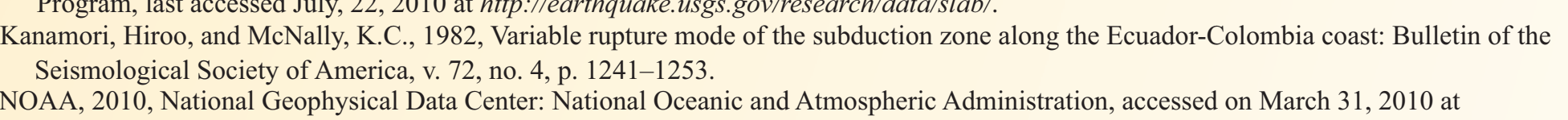

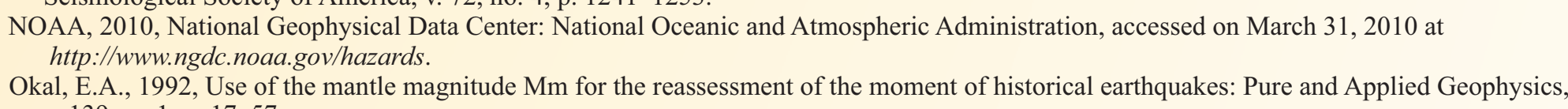

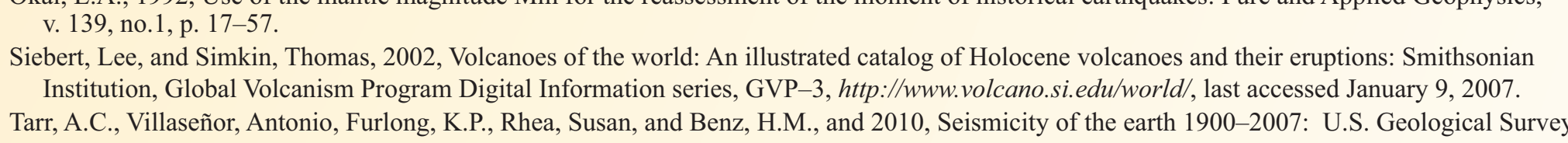

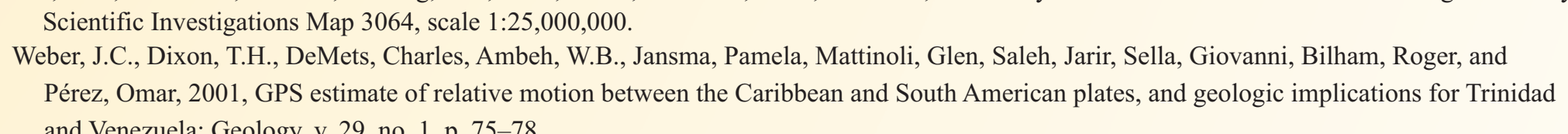

SEISMIC HAZARD AND RELATIVE PLATE MOTION

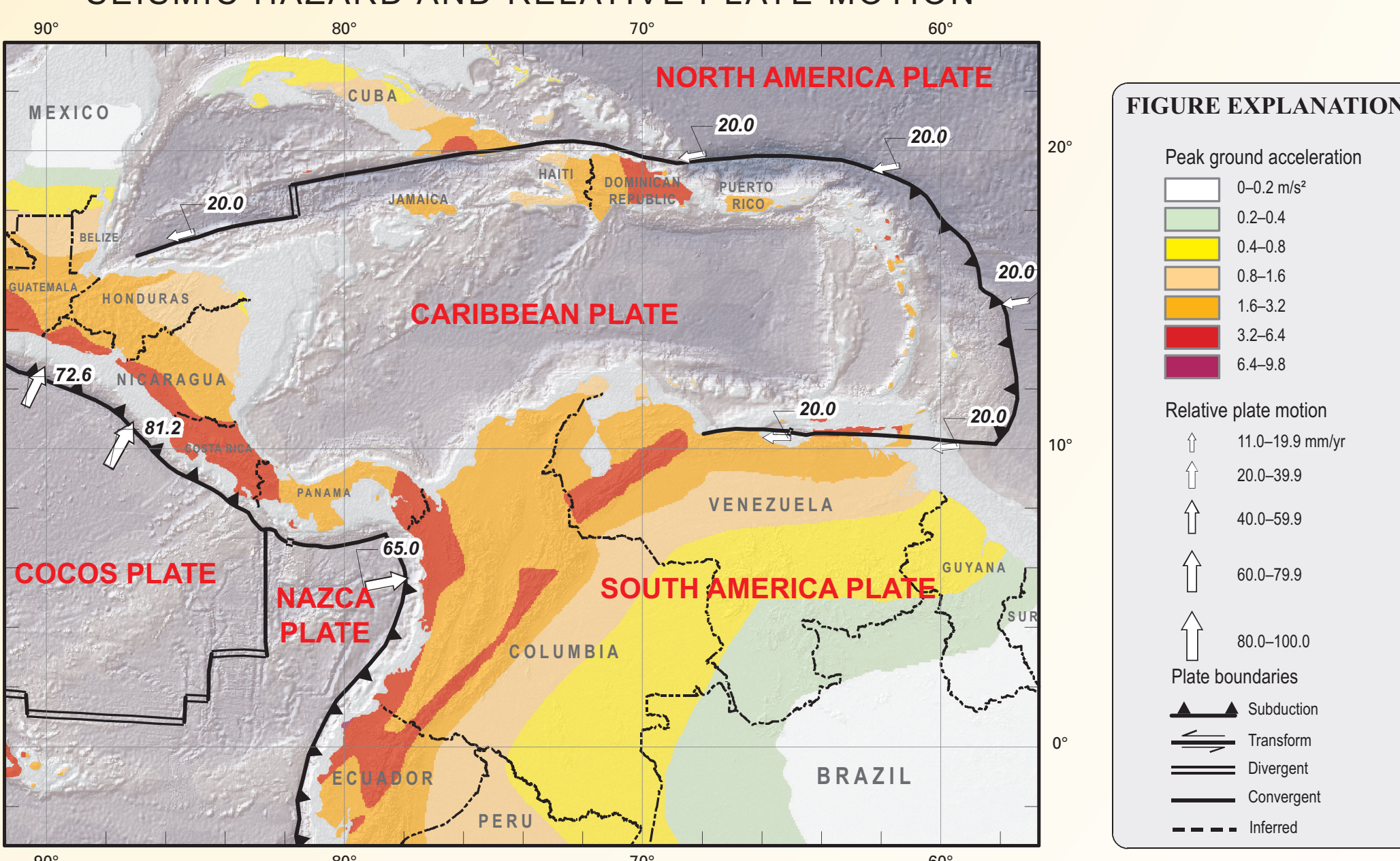

